\title{
Network marketing promotion sand table simulation experiment teaching case design
}

\author{
HuangWufeng \\ National Demonstration Center for Experimental Economics and Management Education(Guangxi \\ University of Finance and Economics) Guangxi NangNing 530000
}

Keywords: Marketing Planning, Marketing Promotion, Sand Table, Simulation Experiment

\begin{abstract}
Network Marketing is a comprehensive course integrating economic disciplines, marketing and e-commerce. With the continuous development of computer network technology and e-commerce, the teaching requirements of the combination of network marketing theory and practice are increasing day by day. According to the real environment of e-business operation, a teaching case is designed to simulate the sale and promotion of specific network products in traditional holidays. This case is of great significance to the subjective initiative of the students, the plan of design and marketing, the analysis of marketing and marketing strategy and the analysis of marketing data.
\end{abstract}

\section{网络营销推广沙盘模拟实验教学案例设计}

\author{
黄武锋 \\ 经济与管理国家级实验教学示范中心（广西财经学院）广西 南宁 530000
}

关键词: 营销策划; 营销推广; 沙盘; 模拟实验

摘要: 网络营销是一门集经济学科、市场营销与电子商务于一体的综合课程。该课程随着计 算机网络技术和电子商务不断发展, 网络营销的理论与实践相结合的教学要求与日俱增。本 文根据电子商务运营的现实环境, 模拟特定的网络产品在传统的节假日进行销售推广而设计 了一个教学案例, 该案例对于学生学习的主观能动性、设计营销计划方案、营销运营推广策 略分析和营销数据分析等有着重大意义。

\section{1. 引言}

网络营销 ${ }^{[1]}$ (e-Marketing) 是一种新型的营销模式, 指以国际互联网网络为基础, 利用数字 化的信息和网络媒体的交互性来辅助营销目标实现的一种新型的营销方式。网络营销是现代 企业利用电子商务平台对传统营销的各个环节进行的信息交互、产品追踪服务、销售决策、 开发潜在客户、维护忠诚客户以及销售管理等各个方面有效补充。

实践教学是当前网络营销课程教学最为有效的要素之一，在贯彻实施教学过程中，如能恰 当运用案例教学法则可以使学生更能真实掌握企业网络营销的运营状况, 把握网络营销的运 营要领。案例教学法以培养学生应用能力为目的, 教师只是组织者和引导者 ${ }^{[2]}$ 。该定义强调 了案例教学法必须强调以学生为学习的主体, 教师的作用在于组织和调动学生学习的主观能 动性, 激发学生学习的兴趣 ${ }^{[3]}$ 。

电子商务网络营销推广是《网络营销》课程中的一个实践环节, 实践案例要求学生使用电 子商务运营沙盘模拟平台，对电子商务网络营销推广业务的营销计划、营销推广方式、营销 广告、友情链接、营销活动等环节进行操作。通过实践, 使学生更加深入理解之前学过的《网 络营销》课程中有关于网络营销的理论紧密联系实际, 使学生在实践操作中掌握和提高分析 
市场、营销策划与推广等实际操作能力, 掌握网络营销的方式、特点以及未来网络营销发展 的趋势。

网络营销推广沙盘模拟实验是从电子商务企业视角出发，提供一个供学生参与到电子商务 企业，并围绕电子商务核心业务并扮演在电子商务活动中不同的角色所需要掌握的业务能力 进行决策演练实训 ${ }^{[4]}$ 。本案例为实验课《网络营销》的教学内容, 学习对象为电子商务专业 的三年级学生。学生通过本实验案例的学习与模拟训练操作, 可以更加深入理解之前学过的

《网络营销》课程中有关于网络营销的理论内容，提高分析市场、营销策划与推广等实际操 作能力。

\section{2. 精选案例}

案例教学法首先需要根据理论内容来选择适当的网络营销案例,案例选择的好坏, 将影响课 堂教学的效果。本案例以模拟的某一公司以 2000 万元启动资金、营销潜在对象上限设定为 2 千万人口为虚拟业务背景, 要求学生使用沙盘模拟平台, 模拟操作包括电子商务网络营销推 广业务的营销计划、营销推广方式、营销广告、友情链接、营销活动等环节。该案例蕴含相 应的网络营销理论知识和网络营销策略, 难易程度适中, 并且结合了现实的电子商务运营环 境，从而也提高学生对该案例探讨的兴趣。

营销推广的目标是开发更多的需求群体和客户群体，让更多的人了解和购买自己公司的产 品 ${ }^{[5]}$ 。目前网络推广的方法、途径繁多, 本案例以网络营销推广业务的重要性及复杂性为背 景, 通过模拟操作推广业务流程, 让学生在实验操作中掌握网络营销推广业务的相关内容。

\section{3. 案例思路与流程}

本案例是根据当前市场的特征以及网络营销的特点, 使用电子商务运营沙盘模拟系统, 组 织学生模拟操作网络营销推广业务, 从而使学生掌握企业网络营销推广业务的相关内容。

本案例的分析思路是模拟企业电子商务网络营销推广运营业务的操作流程，具体分为制订 营销计划、选择营销推广方式、投放营销广告方式选择的决策、确认扩大营销范围的友情链 接以及规划营销活动等环节。

\section{4. 教学内容实施}

根据沙盘软件的基本设置，假设公司的启动资金为2千万元，营销潜在对象上限设定为 $2 千$ 万人口, 在一年 12 个月（假设每月都有一个节日：一月为元旦，二月为春节，三月为妇女节， 四月清明节, 五月为劳动节, 六月为儿童节, 七月为建党节, 八月为建军节, 九月为教师节, 十月为国庆节，十一月为光棍节，十二月为圣诞节）的节假日进行商品的网络营销推广操作。

\section{1 营销计划}

确定销售策略和销售目标金额，以及选择公司销售的产品。销售目标根据设定的节假日特 点来确定，如十一月份的双十一节是中国的狂欢购物节，销售目标肯定是平时的5-10倍; 销 售的品类因服装与天气因素环境有很大的关系，所以可根据节日所在的季度进行选择，如六 一为儿童节, 销售的服装可重点选择儿童类的, 此处操作主要涉及知识点在于设定节假日促 销策略及目标。

\section{2 营销推广}

\subsection{1 竞价排名}

竞价推广是按照客户的点击量进行付费，企业要推广信息出现在搜索结果比较靠前的位 置, 这是一种按效果付费的网络营销推广方式。由于推广信息位置靠前且与用户检索的内容 高度相关，企业以较小的投入成本来快速提升企业自身的品牌知名度，从而提高企业销售产 
品额度达到推广的目的。

\subsubsection{E-mail营销}

电子邮件营销指向潜在的目标用户许可的前提下, 通过电子邮件的方式向他们传递企业品 牌价值信息的一种网络营销手段。利用电子邮件群发高效率的特性，对于开发新客户快速提 升公司业绩非常有效。这也是企业与受众客户进行交流、推广企业品牌提高产品销售额的一 种直销方式。

\subsection{3 营销广告}

网络广告是在PC端、移动终端等载体上做的广告, 也是目前常用的网络营销方法之一。企 业一般通过专业的运营机构把网络广告投放到客户端平台，充分利用众多网页的广告横幅、 网络导航和文本链接等的方法, 在网络平台上按照一定的规格发布电子邮件广告、搜索引擎 关键词广告、搜索固定排名等各种广告，充分利用网络的便捷性，快速传递到受众用户的一 种现代媒体广告方式。由于媒体广告投放的快速性与精准性, 使得网络广告与传统的电视、 报纸等广告相比具有得天独厚的优势，企业往往把现代营销媒体作为品牌推广战略的重要一 部分。

\subsubsection{SEO优化}

SEO是一种利用搜索引擎的技术来提高网站排名优化方式, 排名越高, 推广的信息内容影 响力显然越大。在网站结构技术中, 在网页代码中的 $<$ Meta $>$ 标签属性对于网站的关键词排名 起着决定的作用, 对 $<$ Meta $>$ 标签的搜索引擎的撰写方式将直接影响着网站的排名, 网站排名 的上升显然对营销推广作用是相当大的, 这对于站点内容的收录也是有益的, 因此对每个网 页加上 $<$ Meta $>$ 的属性值是SEO必不可少的环节。 $<$ Meta $>$ 标签中包括有三个对网站排名起着决 定作用的标签, 分别是: <Title $>$ 标题标签、 $<$ Description $>$ 描述标签和 $<$ Keyword $>$ 关键词标签, 设置好这三对标签的相关属性对于网站的排名起到至关重要的作用。

\subsection{5 友情链接}

友情链接在网站推广中作用虽然不是很大，但它对于让更多的搜索引擎收录作用却十分明 显。它往往在具有一定资源互补优势两个网站互相推广，常规操作是在自己的网站主页友情 链接处放置对方网站的网标图片或网站名称, 把超链接的目标设置为对方的网站, 这样使得 网站被受众用户发现的概率大大提高, 对方的网站一旦被探索引擎收录, 自己的网站也跟着 收录进去, 这样达到互相推广的目的。

\subsection{6 营销活动}

网络营销活动一般在特定的节假日前, 企业主要通过传统方式结合互联网的利用, 对各种 商品进行打折优惠促销, 它是营销者围绕一定的主题向消费者传递有企业及产品的优惠信息, 以此吸引更多的消费者购买，从而达到扩大销售量的目的。

\section{5. 教学方法}

\section{1 教师教学方法}

教师采用常规的讲授与演示法, 通过讲解要点以及演示关键操作要点让学生快速理解与掌 握电子商务网络营销的相关操作。

\section{2 小组分工合作式教学}

现实中企业的电子商务运营工作是分工明确、权责分明的，各个岗位之间联系密切、相互 合作又相互制衡。为了更好地模拟电子商务运营的业务流程, 培养学生的合作能力和组织能 力, 在使用电子商务运营沙盘软件完成本案例的实验操作时, 使用小组分工合作式的教学方 
式, 通过小组内的分工合作, 能让学生对电子商务运营的岗位设置、业务流程有更好的理解。

\section{3 课外自学}

由于《网络营销》课程的理论和实践内容十分丰富, 为了充分利用课堂时间, 提高教学效 果, 安排学生课外自学部分相关的内容如《SEO网站营销策略、方法、技巧和案例》（作者: 刘玉萍; 出版社: 清华大学出版社, 出版时间: 2016.1), 并通过提问、作业等方式保证自 学的质量和效果。

\section{6. 教学组织}

\section{1 分组教学。}

教学班 60 名学生, 分为 10 组, 每组最多6人。这样分组方便进行讨论学习, 也方便每组学 员进行分工, 做到每人职责明确, 团结协调。

\section{2 时间安排}

总共教学课时为 32 学时, 具体分配如表 1 所示。

\section{表1 教学时间安排表}

\begin{tabular}{ll}
\hline 时间 & 教学内容 \\
\hline 课前准备 & 要求学生自行复习《网络营销》课程中学过的营销推广理论 \\
\hline 4 课时 & 讲授企业电子商务运营网络营销推广的相关内容 \\
\hline 课前准备 & 要求学生自学《SEO网站营销策略、方法、技巧和案例》资料, 掌握至少一个 \\
& 方法。 \\
\hline 2课时 & 讲解和演示网络营销推广沙盘模拟操作的要点 \\
\hline 4 课时 & 营销计划 \\
\hline 4 课时 & 竞价排名 \\
\hline 4 课时 & E-mal营销 \\
\hline 4 课时 & SEO优化 \\
\hline 8 课时 & 营销活动 \\
\hline 2课时 & 总结与撰写实践报告 \\
\hline
\end{tabular}




\section{3 操作结果评分标准}

\section{表2 操作结果评份标准}

\begin{tabular}{|c|c|c|c|}
\hline \multirow{2}{*}{$\frac{\text { 项目 }}{\text { 营销计划 }}$} & & 要求 & 分值 \\
\hline & & $\begin{array}{l}\text { 能根据本公司的实际情况, 对营销推广目标、营销推广方 } \\
\text { 式有一个清晰的思路, 营销计划符合实际运营情况。 }\end{array}$ & 20 \\
\hline \multirow{5}{*}{ 营销推广 } & 搜索引擎 & $\begin{array}{l}\text { 设置产品的关键词要合理突出, 竞价排名符合本公司实际 } \\
\text { 情况 }\end{array}$ & 10 \\
\hline & E-mal营销 & $\begin{array}{l}\text { 能根据营销活动合理使用邮件营销手段，扩大潜在的客户 } \\
\text { 销售对象 }\end{array}$ & 10 \\
\hline & 营销广告 & $\begin{array}{l}\text { 能根据本公司的财力以及营销目标选择合适的营销广告方 } \\
\text { 式 }\end{array}$ & 20 \\
\hline & SEO优化 & 能据本公司营销的产品对Meta和友情链接进行合理设置 & 15 \\
\hline & 营销活动 & $\begin{array}{l}\text { 能根据产品销售盈利情况合理在沙盘设置的节日进行营销 } \\
\text { 打折活动 }\end{array}$ & 15 \\
\hline 营销效果 & & $\begin{array}{l}\text { 根据营销数据分析, 整个营销推广效果符合本公司营销的 } \\
\text { 目标 }\end{array}$ & 5 \\
\hline 实践报告 & & $\begin{array}{l}\text { 思路清晰、计划严谨、运营能据实际现实、排版整齐、无 } \\
\text { 错别字 }\end{array}$ & 5 \\
\hline
\end{tabular}

\section{7. 结束语}

理论与实践在教学过程中脱节现象在教学过程中往往比较明显, 在“大众创业, 万众创新” 新形势下培养具备深厚营销理论和实际网络营销运营能力的多层次人才成为电子商务专业教 学的当务之急[6]。本实践案例是根据网络营销课程开设的实际情况, 将实践环节的设计由浅 入深、循序渐进、团队协作的综合专题实训任务, 在教学中应注意提高学生的主观能动性。

\section{参考文献}

[1] 冯英健.网络营销基础与实践[M].北京:清华大学出版社,2004:15-16.

[2] 陈国龙网络营销课中的案例教学法[J].职业与教育, 2008:40-41.

[3] 网络营销课程内容的构建---基于财经类院校市场营销专业的思考 [J]. 教育创新, 2009(10):148-149.

[4] 包金龙. 高职网络营销课程教学体系设计研究[J]. 成人教育，2011(01):121-122.

[5] 廖可贵. 试析网络营销专业创业教育的探索与实践---评《网络营销》 [J]. 当代教育科学, 2015(10):70.

[6] 㚞建锋. 基于学生、教师和教学评价者三方视角的课程教学大纲构建---以网络营销课程 为例 $[\mathrm{J}]$. 内蒙古师范大学学报 (教育科学版)，2016(02):72-76. 